\title{
Treatment of Asymptomatic Carriers of Plasmodium falciparum with Artemether-Lumefantrine: Impact on the Prevalence of Anemia
}

\author{
Alfred B. Tiono • Alphonse Ouédraogo • \\ Christine Remy $\cdot$ Kamal Hamed
}

To view enhanced content go to www.infectiousdiseases-open.com

Received: February 1, 2013 / Published online: March 30, 2013

(c) The Author(s) 2013. This article is published with open access at Springerlink.com

\begin{abstract}
Introduction: An investigation of whether treatment of asymptomatic carriers of Plasmodium falciparum with artemetherlumefantrine $(\mathrm{AL})$, in addition to the routine treatment of symptomatic cases with $\mathrm{AL}$, could improve the prevalence of anemia in 18 villages in Burkina Faso.
\end{abstract}

Methods: This was a single-center, controlled, parallel, cluster-randomized study to evaluate

ClinicalTrials.gov \#NCT01256658.

A. B. Tiono $(\square) \cdot$ A. Ouédraogo

Centre National de Recherche et de Formation sur le Paludisme, Ministère de la Santé, O1BP 2208 Ouagadougou, Burkina Faso e-mail: t.alfred@fasonet.bf

C. Remy

Novartis Pharma AG, 4002, Basel, Switzerland

K. Hamed

Novartis Pharmaceuticals Corporation, One Health Plaza, East Hanover, NJ 07936-1080, USA

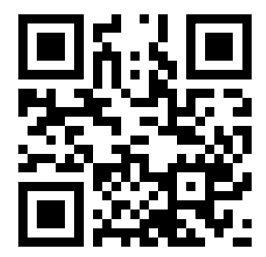

Enhanced content for this article is

available on the journal web site:

www.infectiousdiseases-open.com the effect of systematic treatment of $P$. falciparum asymptomatic carriers at a community level on hemoglobin ( $\mathrm{Hb}$ ) levels and anemic status of children ( $<5$ years) and adults during four screening campaigns carried out over a 12-month period, compared with no treatment of asymptomatic carriers.

Results: The change in $\mathrm{Hb}$ level in all asymptomatic carriers aged $>6$ months from Day 1 to Day 28 of the first campaign was $+0.53 \mathrm{~g} / \mathrm{dl}$ (from 11.81 to $12.33 \mathrm{~g} / \mathrm{dl}$ ) in the intervention arm vs. $-0.21 \mathrm{~g} / \mathrm{dl}$ (from 12.06 to $11.86 \mathrm{~g} / \mathrm{dl})$ in the control arm $(P<0.001)$. During the same period, the proportion of asymptomatic carriers aged $>6$ months to $<5$ years with anemia in the intervention arm decreased by $31.1 \%$ (from $75.7 \%$ to $44.6 \%$ ), compared with a decrease of $4.7 \%$ (from $76.3 \%$ to $71.6 \%$ ) in the control arm. Over 12 months, the proportion of asymptomatic carriers with anemia (mild, moderate, or severe) was reduced in both arms.

Conclusion: Systematic screening and treatment of asymptomatic carriers of $P$. falciparum with $\mathrm{AL}$ at the community level can reduce the prevalence of anemia in children in the short term (28 days), although the effect was not maintained at 12 months. 
Keywords: Anemia; Artemether-lumefantrine; Asymptomatic carriers; Hemoglobin; Infectious disease; Malaria; Plasmodium falciparum

\section{INTRODUCTION}

Recent application of malaria control strategies has succeeded in reducing the malaria burden in endemic regions [1-5], yet malarial anemia remains a major cause of morbidity and mortality [6, 7]. Plasmodium falciparum malaria in Kenyan children was reported to account for up to $75 \%$ of anemia-associated deaths and $9 \%$ of all deaths [7]. Furthermore, children with severe malarial anemia had a mortality rate of $8.6 \%$, compared with $3.6 \%$ in children with severe anemia due to other causes [7].

Malarial anemia is well known as a major complication of symptomatic parasitemia. Less well known is that it is also significantly associated with low-density asymptomatic parasitemia in children [8, 9]. This, coupled with the fact that a large proportion (dependant on factors such as population age, natural immunity, and transmission rate) of infections in endemic areas are asymptomatic [10-14], means that the potential to further reduce the burden of malarial anemia through the treatment of asymptomatic carriers is promising.

It is already known that interventions that reduce malaria transmission, such as insecticide-treated nets and chemoprophylaxis, can improve hemoglobin ( $\mathrm{Hb})$ levels in children [15-17], and that treatment of asymptomatic children can improve their cognitive ability, possibly as a result of raised $\mathrm{Hb}$ levels [18]. However, little is known about the effect of community-level treatment of asymptomatic carriers on $\mathrm{Hb}$ levels. Reducing malaria transmission within a population through the systematic screening and treatment of asymptomatic persons could potentially improve Hb levels.

This cluster-randomized trial of 18 villages in Saponé, Burkina Faso, investigated whether systematic screening and treatment of asymptomatic carriers of $P$. falciparum with artemether-lumefantrine (AL) during three community screening campaigns (Campaigns 1-3) could reduce the burden of malaria and whether this intervention, in addition to the routine treatment of symptomatic $P$. falciparum carriers with $\mathrm{AL}$, could improve $\mathrm{Hb}$ levels and reduce the prevalence of anemia. Primary outcomes were the number of microscopyconfirmed cases of symptomatic malaria with a parasite density $>5,000 / \mu \mathrm{l}$ per person-year in infants and children $<5$ years of age and the change in $\mathrm{Hb}$ level from Day 1 to Day 28 of Campaign 1 in asymptomatic carriers $>6$ months of age, between the intervention and control arm. Results from the first primary outcome showed that systematic screening with a rapid diagnostic test (RDT) and treatment of asymptomatic carriers did not reduce clinical malaria incidence in the subsequent transmission season. The number of symptomatic malaria episodes at 12 months (microscopy-confirmed symptomatic malaria episodes including fever and a parasite density $>5,000 / \mu \mathrm{l}$ ) per person-year in infants and children aged $<5$ years was $1.69(\mathrm{SD} \pm 0.436)$ in the intervention arm vs. $1.60(\mathrm{SD} \pm 0.526)$ in the control arm $(P=0.3482)$. The number of symptomatic malaria episodes of any parasite density per person-year in infants and children aged <5 years was also not significantly different between the two arms [19]. Herein, the authors report on the changes in Hb levels and prevalence of anemia in asymptomatic carriers and at community level. AL has demonstrated high cure rates with a good 
safety and tolerability profile in $P$. falciparum malaria in many different populations around the world, consistently achieving 28-day polymerase chain reaction (PCR)-corrected cure rates of $>95 \%$, and rapidly clearing parasitemia and fever [20]. AL has been included on the World Health Organization (WHO) Model List of Essential Medicines since March 2002 [21].

\section{MATERIALS AND METHODS}

Full study methodology has previously been published by Tiono et al. [19].

\section{Study Design}

This was a single-center, controlled, parallel, cluster-randomized study that evaluated the effect of systematic treatment of $P$. falciparum asymptomatic carriers at a community level on $\mathrm{Hb}$ levels and anemic status of children ( $<5$ years) and adults over a 12-month period, compared with no treatment of asymptomatic carriers. The study was carried out between November 2010 and February 2012. Clusters were randomized and assigned in a 1:1 ratio to the control or intervention arm.

During the implementation phase of the study, intervention and control village inhabitants participated in Campaigns 1-3 that took place approximately 1 month apart, before the start of the rainy season. Campaign 4 was conducted after the rainy season had ended to mark the end of the study at 12 months (Fig. 1) [19]. At each campaign, finger-prick blood samples were taken from the entire study population in the intervention arm and a randomly selected $40 \%$ in the control arm for screening for $P$. falciparum asexual forms and gametocytes, and assessment of Hb level (only performed during Campaigns 1 and 4). In the intervention arm, the population was screened using RDT (First Response ${ }^{\circledR}$ Malaria Ag, Premier Medical Corp Ltd., Nani-Daman, India). Subjects with a positive RDT on Day 1 of Campaign 1 had blood samples taken for microscopy and $\mathrm{Hb}$ level assessment on Day 28 of Campaign 1. Subjects in the control arm were not screened by RDT-microscopy alone with delayed reading was used to ensure that study personnel and screened subjects remained unaware of a subject's status.

\section{Study Population}

The study took place in the health district of Saponé, about $50 \mathrm{~km}$ south of Ouagadougou in Burkina Faso, an area with marked seasonal (June to November) $P$. falciparum malaria transmission [22]. Eighteen clusters, each comprising of one village, were selected for inclusion in the trial. All inhabitants of each cluster were invited to participate in the trial. Written informed consent was received from all study participants or their legal guardians.

\section{Interventions}

All members of the study population who were diagnosed by RDT as asymptomatic carriers in the intervention arm, or who were diagnosed with symptomatic malaria confirmed by RDT in the intervention and control arms, received AL. Subjects with contraindications for AL received alternative treatment according to national guidelines. All households received long-lasting insecticide-impregnated bednets (LLINs; Olyset ${ }^{\circledR}$ nets [Sumitomo Chemical Co, Ltd, Tokyo, Japan]) prior to the implementation phase.

\section{Monitoring}

Throughout the study, community healthcare workers visited households to check and 


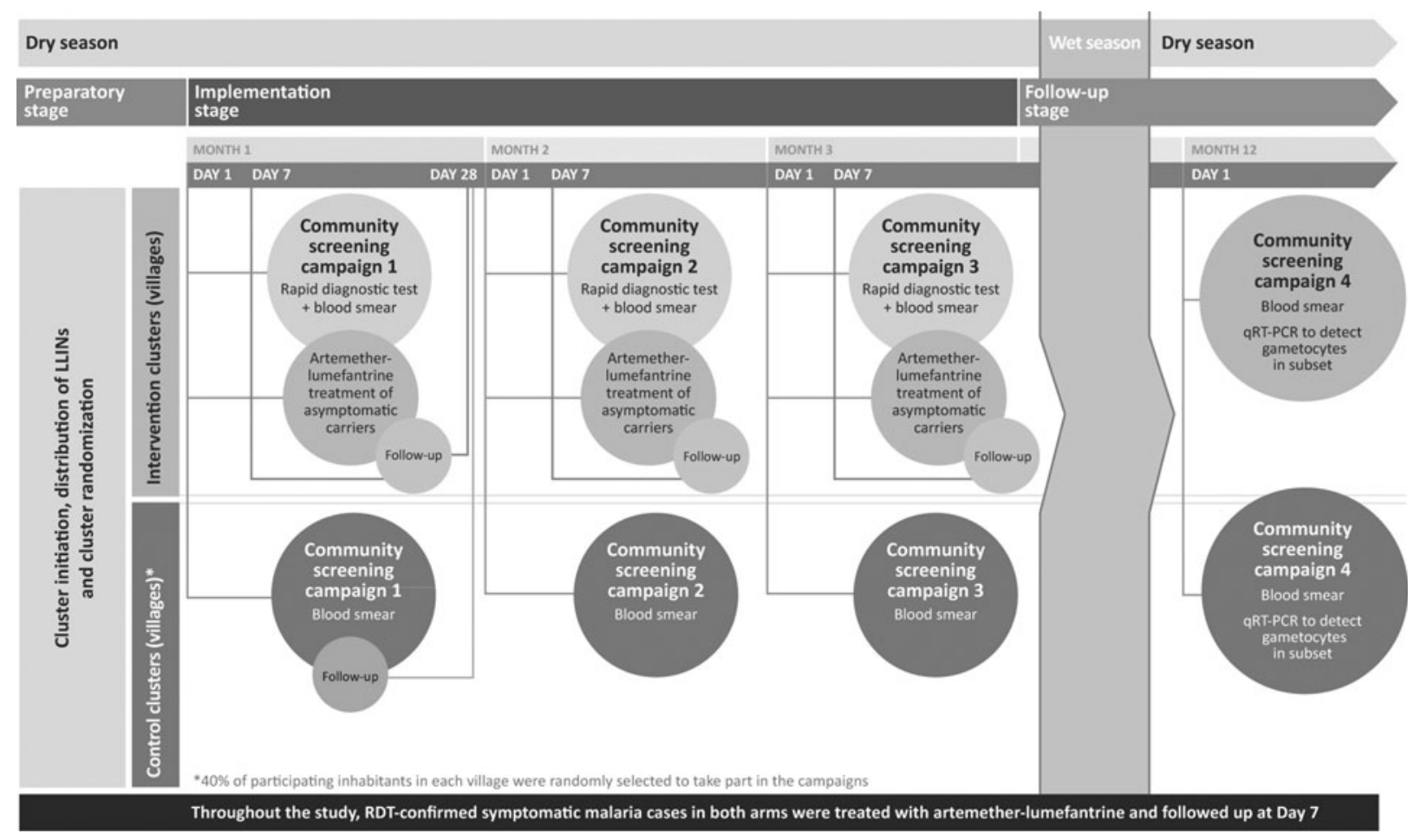

Fig. 1 Single-center, controlled, parallel, cluster-randomized, 12-month prospective study. $q R T-P C R$ real-time quantitative reverse transcription polymerase chain reaction, $R D T$ rapid diagnostic test

document treatment adherence of asymptomatic carriers and those with symptomatic malaria through the use of a drug accountability log and tablet counts. The use of LLINs was checked at the home visits conducted at least every two months, and additional training was provided when required. Adverse events and serious adverse events were also recorded, as previously described by Tiono et al. [19].

\section{Study Medication}

All individuals with a positive RDT in the intervention arm received $\mathrm{AL} / \mathrm{AL}$ dispersible (20 $\mathrm{mg}$ artemether and $120 \mathrm{mg}$ lumefantrine), adjusted according to body weight, twice a day for three consecutive days. The first dose was supervised. Individuals with contraindications to AL and AL dispersible, or any female who was either in the first trimester of pregnancy or of childbearing potential who did not take the urine pregnancy test, received alternative treatment. Subjects with $\mathrm{Hb}<5 \mathrm{~g} / \mathrm{dl}$ on Day 1 of Campaign 1 were referred to the local healthcare facility where hematinics were given. Full details have previously been published by Tiono et al. [19].

\section{Laboratory Methods}

$\mathrm{Hb}$ level was measured using the HemoCue ${ }^{\circledR} \mathrm{Hb}$ $201+$ rapid test (Ängelholm, Sweden) using blood collected by finger-prick on Day 1 and Day 28 of Campaign 1 and on Day 1 of Campaign 4.

\section{Statistical Analysis}

Data analysis, performed with SAS ${ }^{\circledR}$ Software (Version 9.3; SAS Institute, Cary, NC, USA) of the SAS System for Unix, followed a cluster-level 
approach where a summary measure per cluster was used. A one-sided $t$ test of equal means was conducted to a significance level of 0.05 for all outcome measures. The distribution of Hb levels at different time points (Days 1 and 28 of Campaign 1, and Day 1 of Campaign 4) was presented as a box plot.

\section{Outcome Measures and Endpoints}

In order to quantify a potential direct benefit on $\mathrm{Hb}$ levels associated with $\mathrm{AL}$ treatment in asymptomatic carriers, outcomes were assessed in subjects with microscopy-confirmed asymptomatic malaria detected on Day 1 of Campaign 1. Separate outcomes aimed at assessing the potential improvement of community-wide Hb levels were also conducted.

\section{Outcomes in Microscopy-Confirmed Asymptomatic Carriers}

The first primary endpoint was the number of RDT and microscopy-confirmed cases of symptomatic malaria with a parasite density $>5,000 / \mu \mathrm{l}$ per person-year in infants and children $<5$ years of age in the intervention compared with the control arm. The second primary endpoint was the change in $\mathrm{Hb}$ level from Day 1 to Day 28 of Campaign 1 in asymptomatic carriers $>6$ months of age, between the intervention and control arm.

Secondary endpoints were the proportion of all asymptomatic carriers aged $>6$ months to $<5$ years who increased their $\mathrm{Hb}$ level by at least $0.5 \mathrm{~g} / \mathrm{dl}$ during Campaign 1 and the change in anemic status over time (from Day 1 to Day 28 of Campaign 1 and to Day 1 of Campaign 4) in asymptomatic carriers aged $>6$ months up to $<5$ years. Anemic status was defined as severe anemia $=\mathrm{Hb}<5 \mathrm{~g} / \mathrm{dl}$, moderate anemia $=\mathrm{Hb} 5$ to $<8 \mathrm{~g} / \mathrm{dl}$, mild anemia $=\mathrm{Hb} 8$ to $<11 \mathrm{~g} / \mathrm{dl}$, no anemia $=\mathrm{Hb} \geq 11 \mathrm{~g} / \mathrm{dl}$.

\section{Outcomes in All Subjects (Community Level)}

Secondary endpoints were the change in $\mathrm{Hb}$ levels from Campaign 1 to Campaign 4 in children aged $>6$ months to $<5$ years, 5-9 years and 10-14 years, as well as in subjects aged $\geq 15$ years. The distribution of $\mathrm{Hb}$ levels at different time points (Days 1 and 28 of Campaign 1, and Day 1 of Campaign 4), for the different age groups was also assessed.

\section{Ethics Section}

The protocol and the informed consent form were reviewed and approved by the Centre National de Recherche et de Formation sur le Paludisme Institutional Review Board and by the National Ethical Committee for Health Research of Burkina Faso. Prior to study initiation, a community meeting was held in each of the selected clusters to discuss the study with the community. The freedom of each individual household and each household member to decide on participation was discussed to minimize the potential influence of key opinion leaders in each cluster. Individual informed consent was obtained from each participant during a visit to the household before any study procedure. All procedures followed were in accordance with the ethical standards of the responsible committee on human experimentation (institutional and national) and with the Helsinki Declaration of 1975 , as revised in 2000. Informed consent was obtained from all participants included in the study.

\section{RESULTS}

A total of 6,817 persons in the intervention arm and 7,258 persons in the control arm were enrolled, and $86.5 \%(5,897)$ of the persons in the intervention arm and $89.7 \%(6,510)$ of the persons in the control arm completed the study 
(Table 1). Loss to follow-up (the most common reason for discontinuation) was slightly more common in the intervention arm (12.3\%) than in the control arm (9.1\%). Full details were published by Tiono et al. [19].

The intervention and control arms were comparable in terms of demographic characteristics with the exception of ethnicity: $90.6 \%$ of the intervention arm was Mossi and $8.7 \%$ was Fulani, while the control was $95.7 \%$ Mossi and 3.8\% Fulani.

Table 1 Study population baseline demographicsindividual-level data

\begin{tabular}{|c|c|c|}
\hline Characteristic & $\begin{array}{l}\text { Intervention } \\
\text { arm }\end{array}$ & $\begin{array}{l}\text { Control } \\
\text { arm }\end{array}$ \\
\hline Number enrolled & 6,817 & 7,258 \\
\hline $\begin{array}{l}\text { Born after cluster } \\
\text { initiation }(\%)\end{array}$ & $151(2.2)$ & $128(1.8)$ \\
\hline $\begin{array}{l}\text { Immigrant during } \\
\text { the study }(\%)\end{array}$ & $349(5.1)$ & $207(2.9)$ \\
\hline Persons completed (\%) & $5,897(86.5)$ & $6,510(89.7)$ \\
\hline Male sex (\%) & 46.4 & 47.4 \\
\hline \multicolumn{3}{|l|}{ Age at Campaign 1 Day 1} \\
\hline Mean (years) & 24.1 & 23.4 \\
\hline \multicolumn{3}{|l|}{ Age group (\%) } \\
\hline$\leq 6$ months & 2.1 & 1.5 \\
\hline$>6$ months to $<5$ years & 14.9 & 14.2 \\
\hline $5-9$ years & 15.8 & 16.6 \\
\hline $10-14$ years & 15.5 & 15.3 \\
\hline$\geq 15$ years & 51.7 & 52.5 \\
\hline \multicolumn{3}{|l|}{ Ethnicity (\%) } \\
\hline Mossi & 90.6 & 95.7 \\
\hline Fulani & 8.7 & 3.8 \\
\hline Bissa & 0.01 & 0.03 \\
\hline Gourounsi & 0.03 & 0.2 \\
\hline Other & 0.7 & 0.3 \\
\hline
\end{tabular}

\section{Outcomes in Microscopy-Confirmed Asymptomatic Carriers}

There was a significant difference in the change in Hb levels from Day 1 to Day 28 of Campaign 1 for all asymptomatic carriers aged $>6$ months (primary endpoint). The change in $\mathrm{Hb}$ level was $+0.53 \mathrm{~g} / \mathrm{dl}$ (from 11.81 to $12.33 \mathrm{~g} / \mathrm{dl}$ ) in the intervention arm vs. $-0.21 \mathrm{~g} / \mathrm{dl}$ (from 12.06 to $11.86 \mathrm{~g} / \mathrm{dl})$ in the control arm $(P<0.001)$. Following this trend, significantly more asymptomatic carriers aged $>6$ months to $<5$ years raised their $\mathrm{Hb}$ level by $\geq 0.5, \geq 1.0$, $\geq 1.5$, and $\geq 2.0 \mathrm{~g} / \mathrm{dl}$ from Day 1 to Day 28 (Campaign 1) in the intervention arm than in the control arm (Fig. 2).

Larger increases in $\mathrm{Hb}$ were seen in the intervention arm relative to the control arm in subjects with medium and high baseline parasite densities as compared with those with low densities (Fig. 3).

A more substantial improvement in the proportion of asymptomatic carriers aged $>6$ months to $<5$ years with anemia (mild, moderate or severe) was seen in the intervention arm than in the control arm over the first 28 days (Day 1 to Day 28 of Campaign $1)$. The proportion of asymptomatic carriers with anemia in the intervention arm decreased by $31.1 \%$ (from $75.7 \%$ to $44.6 \%$ ), compared with a decrease of $4.7 \%$ (from $76.3 \%$ to $71.6 \%$ ) in the control arm (Fig. 4).

Over 12 months, the proportion of asymptomatic carriers aged $>6$ months up to $<5$ years with anemia (mild, moderate or severe) decreased in both arms (Day 1 of Campaign 1 to Campaign 4). The proportion in the intervention arm decreased by $29.9 \%$ (from $75.7 \%$ to $45.8 \%$ ), compared with a decrease of $36.8 \%$ (from $76.3 \%$ to $39.5 \%$ ) in the control arm (Fig. 4). However, there was no marked difference in the reduction of 


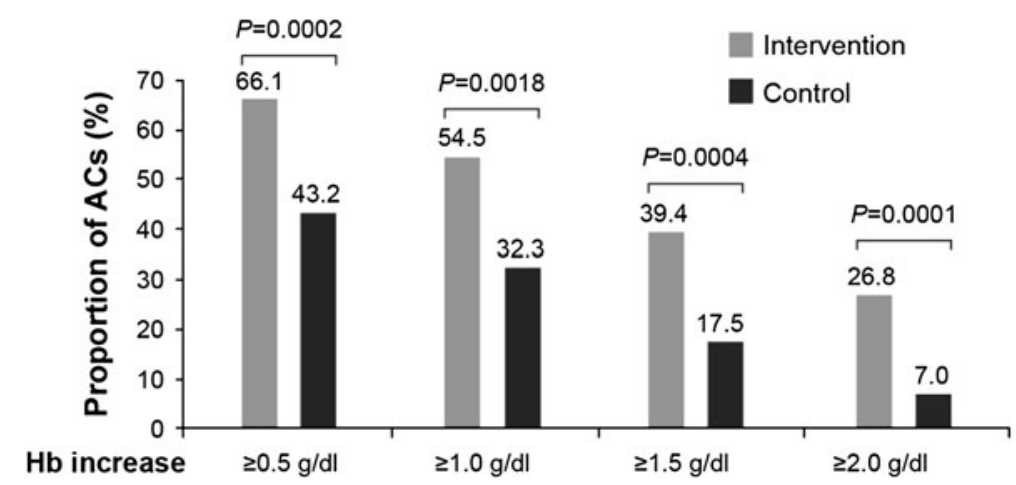

Fig. 2 Proportion of all asymptomatic carriers aged $>6$ months to $<5$ years with an increase in hemoglobin (Hb) level from Day 1 to Day 28 of Campaign 1. ACs asymptomatic carriers

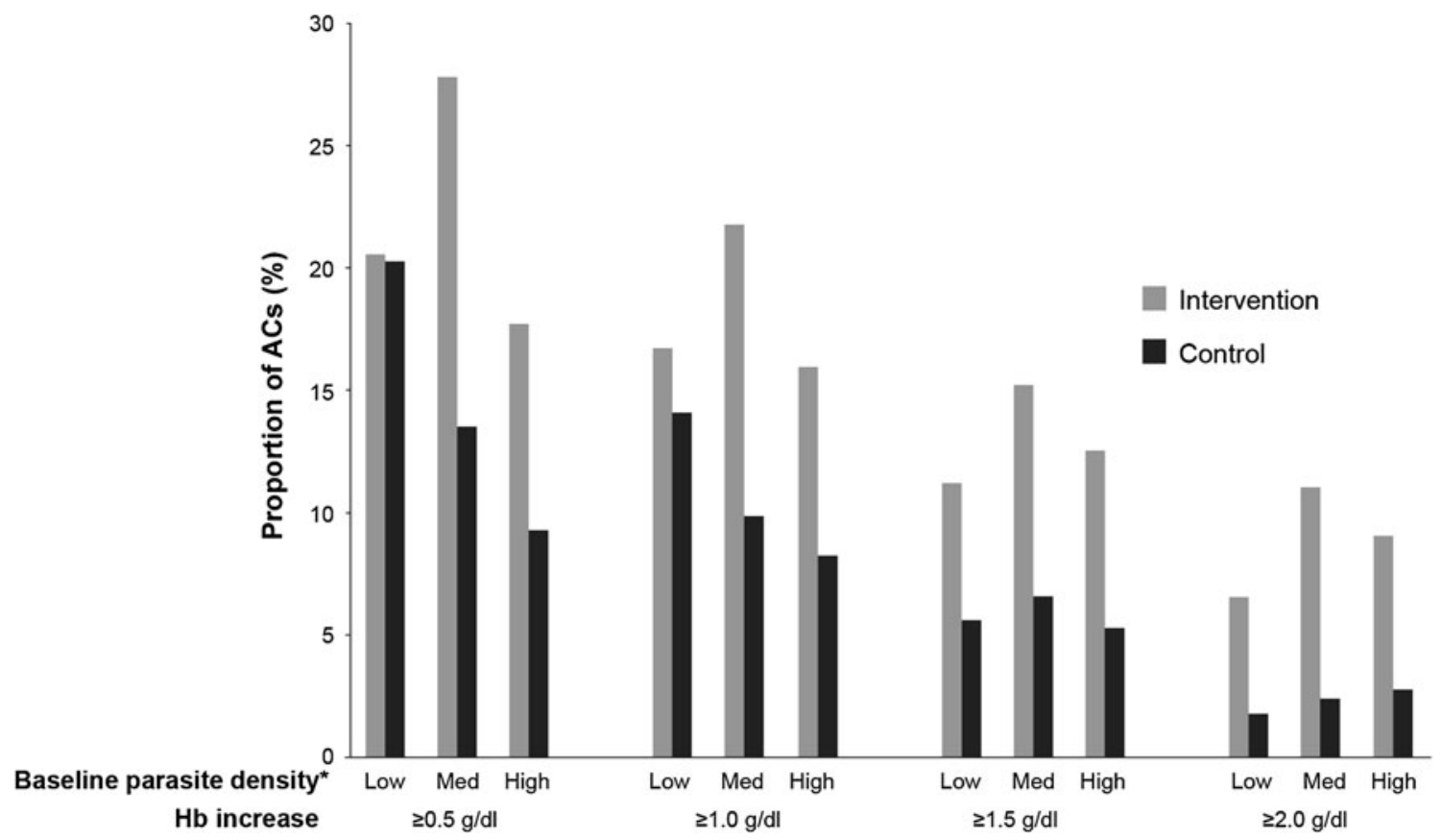

Fig. 3 Proportion of all asymptomatic carriers aged $>6$ months to $<5$ years with an increase in hemoglobin (Hb) level from Day 1 to Day 28 of Campaign 1, stratified

asymptomatic carriers with anemia between each arm over this 12-month period.

\section{Outcomes in All Subjects (Community Level)}

There was no significant difference in the increase in $\mathrm{Hb}$ from Campaign 1 to 4 in by baseline parasite density. $A C s$ asymptomatic carriers. ${ }^{*}$ Low $<1,000 / \mu \mathrm{l}$, Medium (Med) 1,000-4,999/ $\mu$ l, High $\geq 5,000 / \mu \mathrm{l}$

subjects aged $>6$ months to $<5$ years between the two arms. The change in $\mathrm{Hb}$ level was $+0.76 \mathrm{~g} / \mathrm{dl}$ (from 10.24 to $10.99 \mathrm{~g} / \mathrm{dl}$ ) in the intervention arm vs. $+1.08 \mathrm{~g} / \mathrm{dl}$ (from 10.04 to $11.13 \mathrm{~g} / \mathrm{dl})$ in the control arm $(P=0.9318)$.

The difference between the increase in $\mathrm{Hb}$ from Campaign 1 to 4 in subjects aged 5-9, $10-14$, and $\geq 15$ years in the two arms was not 

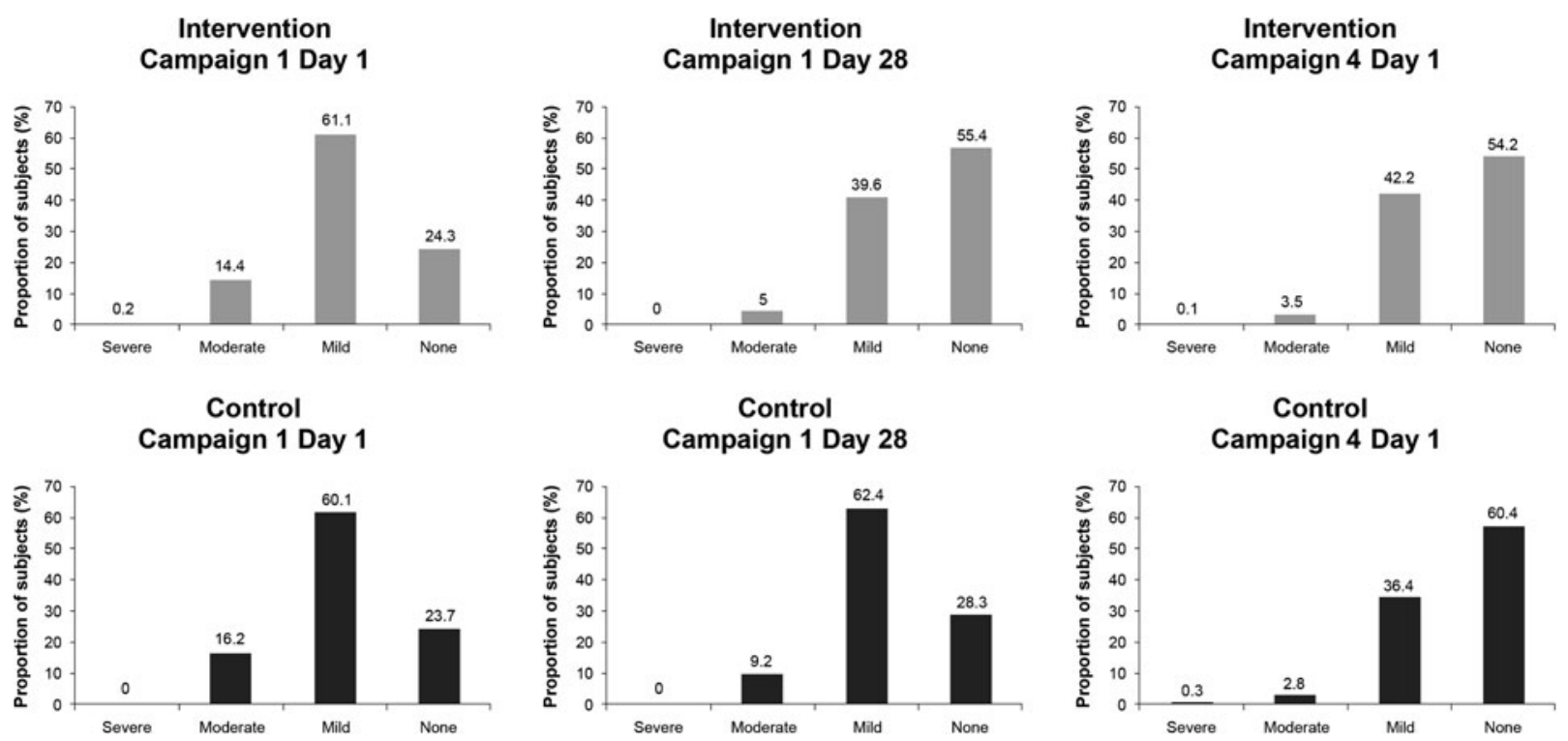

Fig. 4 Reduction in anemia in asymptomatic carriers aged $>6$ months up to $<5$ years over 28 days and 12 months

significant. Hb levels at Campaign 4 in these age groups were similar to $\mathrm{Hb}$ levels in populations without endemic malaria, and there was a trend of increasing $\mathrm{Hb}$ level with increasing age: children aged 5-9 years had a mean $\mathrm{Hb}$ of 11.97 vs. $12.13 \mathrm{~g} / \mathrm{dl}$ (intervention vs. control arms), and children aged 10-14 years had a mean $\mathrm{Hb}$ of 12.58 vs. $12.72 \mathrm{~g} / \mathrm{dl}$, while study participants aged $\geq 15$ years had a mean $\mathrm{Hb}$ of 13.25 vs. $13.42 \mathrm{~g} / \mathrm{dl}$.

\section{Distribution of Hb Levels (All Subjects)}

Hb levels within both study arms were similarly distributed on Days 1 and 28 of Campaign 1, and on Day 1 of Campaign 4, with the majority of the Hb levels falling within the outer limits. There was little difference between the study arms in the distribution of Hb levels on Day 1 and Day 28 of Campaign 1 and on Day 1 of Campaign 4 (Fig. 5).

\section{DISCUSSION}

In this study, community screening and targeted treatment of asymptomatic carriers of
$P$. falciparum malaria had a significant impact on short-term (28 days) Hb levels in these asymptomatic carriers, including significantly improving $\mathrm{Hb}$ levels in all asymptomatic carriers >6 months, and reducing the incidence of anemia in asymptomatic carriers aged $>6$ months to $<5$ years by over $30 \%$. However, more research is needed to understand if this is a direct effect of $\mathrm{AL}$ therapy. While it is known that $\mathrm{AL}$ has a consistently high efficacy and safety in the treatment of $P$. falciparum malaria [20], some factors in this study, such as the concurrent treatment of all symptomatic cases in both arms, and the use of LLINs, may have contributed to the improved $\mathrm{Hb}$ levels. It should be noted that these short-term improvements in $\mathrm{Hb}$ levels did correlate with the reduction in carriage of asexual forms and gametocytes seen in these asymptomatic carriers after 28 days of AL therapy (there was a significant reduction in asymptomatic and gametocyte carriage from baseline to the assessment at the beginning of Campaigns 2 and 3) [19]. Only $0.2 \%$ of patients in the 


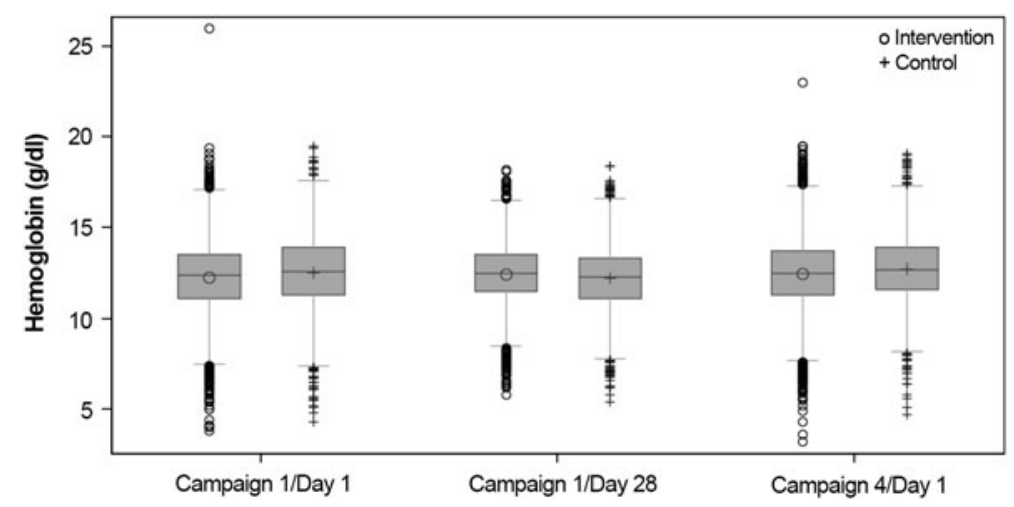

Fig. 5 Distribution of hemoglobin (Hb) levels in all subjects on Day 1, Day 28, and at 12 months

intervention arm and none in control arm required hematinic treatment (for $\mathrm{Hb}<5 \mathrm{~g} / \mathrm{dl}$ on Day 1 of Campaign 1), making it unlikely that this intervention influenced the overall Hb changes.

While the interventions in the study resulted in a significantly greater increase in $\mathrm{Hb}$ in asymptomatic carriers aged $>6$ months over 28 days in the intervention arm than in the control arm, this improvement was not of a sufficient magnitude to be considered clinically meaningful. This was probably because the mean baseline $\mathrm{Hb}$ level in both arms was within the normal range (intervention: $11.81 \mathrm{~g} / \mathrm{dl}$; control $11.86 \mathrm{~g} / \mathrm{dl}$ ), making a large increase in $\mathrm{Hb}$ unlikely. However, over these 28 days, it is encouraging that (a) a significantly larger proportion of asymptomatic carriers aged $>6$ months up to $<5$ years in the intervention arm raised their $\mathrm{Hb}$ levels by $\geq 2.0 \mathrm{~g} / \mathrm{dl}$ than in the control arm (Fig. 2), and (b) the proportion of these asymptomatic carriers with anemia in the intervention arm decreased substantially more than that in the control arm $(31.1 \%$ vs. 4.7\%; Fig. 4).

It is interesting to note that while the reduction in anemia in asymptomatic carriers was sustained in the intervention arm over 12 months, anemia was also reduced in the control arm over this period. This suggests a possible study effect owing to the availability of $\mathrm{AL}$ for all confirmed cases of symptomatic malaria and the provision of an LLIN to every participant in the study. A recent study, which examined the coverage of malaria control interventions in Burkina Faso, reported that $59 \%$ of households in the study population owned an insecticide-treated bednet (ITN) and only $34 \%$ of children under 5 years of age with a reported malaria case were treated with an artemisinin-based combination therapy (ACT) [23]. It is, therefore, possible that receipt of an LLIN by every study participant increased the use of ITNs in both study arms. A Cochrane Review of the impact of medicated bednets concluded that sleeping under one improved $\mathrm{Hb}$ level in children by $1.7 \%$ packed cell volume [24]. Additionally, the high level of general medical attention and easy availability of a high-quality ACT to treat confirmed malaria cases throughout the duration of the study may have contributed to a reduction in parasite levels in both arms as compared with baseline [19].

While the impact of improved Hb levels on quality of life is not known, it has previously been shown that asymptomatic infection can also affect cognitive performance, and that treatment of asymptomatic malaria improves children's cognitive ability [18]. It has also been shown, through fixed effects estimates, 
that asymptomatic malaria and the presence of $P$. falciparum malaria parasites have a direct, causal correlation with educational achievement and cognitive performance in primary school children [25]. Further research is needed to understand the potential benefit on quality of life of improving $\mathrm{Hb}$ levels through treatment of asymptomatic carriers with AL. This is particularly pertinent as asymptomatic carriers tend not to seek treatment yet may benefit from AL therapy.

$\mathrm{Hb}$ levels in the community (all subjects) increased over 12 months, with no significant difference between the intervention and control arms in mean levels or distribution, and median and 25th percentile $\mathrm{Hb}$ levels remained above the defined limit for anemia at all times in both arms. Again, the treatment of all symptomatic cases, and the widespread use of LLINs in both arms, could make it difficult to identify any direct benefit on $\mathrm{Hb}$ levels due to the treatment of asymptomatic carriers in the intervention arm.

\section{CONCLUSION}

This study demonstrates that systematic screening and treatment of asymptomatic carriers of $P$. falciparum with $\mathrm{AL}$ at the community level may improve $\mathrm{Hb}$ levels and reduce the prevalence of anemia in asymptomatic children over the short term. Further research is needed to establish whether these $\mathrm{Hb}$ improvements are linked directly to the treatment of asymptomatic carriers with AL and to quantify the clinical significance of any treatment-related $\mathrm{Hb}$ improvements. No longer-term (12 months) $\mathrm{Hb}$ improvements in asymptomatic carriers, or at a community level, were noted, although these outcomes were possibly influenced by confounding factors, such as the treatment of all confirmed cases of symptomatic malaria with $\mathrm{AL}$ and the provision of an LLIN to every participant in the study.

\section{ACKNOWLEDGMENTS}

Graeme Baldwin from PreScript Communications provided editorial support sponsored by Novartis Pharma AG. The study was funded by Novartis Pharma AG and the study sponsors were involved in study design, data analysis, data interpretation, and writing of the report. Dr. Tiono is the guarantor for this article, and takes responsibility for the integrity of the work as a whole.

Conflict of interest. Alfred B. Tiono received honoraria from Novartis Pharma AG, Basel, Switzerland, to attend advisory board meetings to discuss this study and manuscript. Alphonse Ouédraogo received honoraria from Novartis Pharma AG, Basel, Switzerland, to attend advisory board meetings to discuss this study and manuscript. Christine Remy is an employee of Novartis Pharma AG. Kamal Hamed is an employee of Novartis Pharmaceuticals Corporation.

Compliance with Ethics Guidelines. The protocol and the informed consent form were reviewed and approved by the Centre National de Recherche et de Formation sur le Paludisme Institutional Review Board and by the National Ethical Committee for Health Research of Burkina Faso. Prior to study initiation, a community meeting was held in each of the selected clusters to discuss the study with the community. The freedom of each individual household and each household member to 
decide on participation was discussed to minimize the potential influence of key opinion leaders in each cluster. Individual informed consent was obtained from each participant during a visit to the household before any study procedure. All procedures followed were in accordance with the ethical standards of the responsible committee on human experimentation (institutional and national) and with the Helsinki Declaration of 1975, as revised in 2000. Informed consent was obtained from all participants included in the study.

Open Access. This article is distributed under the terms of the Creative Commons Attribution Noncommercial License which permits any noncommercial use, distribution, and reproduction in any medium, provided the original author(s) and the source are credited.

\section{REFERENCES}

1. Ogutu B, Tiono AB, Makanga M, et al. Treatment of asymptomatic carriers with artemetherlumefantrine: an opportunity to reduce the burden of malaria? Malar J. 2010;9:30.

2. Otten M, Aregawi M, Were W, et al. Initial evidence of reduction of malaria cases and deaths in Rwanda and Ethiopia due to rapid scale-up of malaria prevention and treatment. Malar J. 2009;8:14.

3. Bhattarai A, Ali AS, Kachur SP, et al. Impact of artemisinin-based combination therapy and insecticide-treated nets on malaria burden in Zanzibar. PLoS Med. 2007;4:e309.

4. Ceesay SJ, Casals-Pascual C, Erskine J, et al. Changes in malaria indices between 1999 and 2007 in The Gambia: a retrospective analysis. Lancet. 2008;372: 1545-54.

5. Sharp BL, Kleinschmidt I, Streat E, et al. Seven years of regional malaria control collaborationMozambique, South Africa, and Swaziland. Am J Trop Med Hyg. 2007;76:42-7.

6. Murphy SC, Breman JG. Gaps in the childhood malaria burden in Africa: cerebral malaria, neurological sequelae, anemia, respiratory distress, hypoglycemia, and complications of pregnancy. Am J Trop Med Hyg. 2001;64:57-67.

7. Newton CR, Warn PA, Winstanley PA, et al. Severe anaemia in children living in a malaria endemic area of Kenya. Trop Med Int Health. 1997;2:165-78.

8. McElroy PD, ter Kuile FO, Lal AA, et al. Effect of Plasmodium falciparum parasitemia density on hemoglobin concentrations among full-term, normal birth weight children in western Kenya, IV. The Asembo Bay Cohort Project. Am J Trop Med Hyg. 2000;62:504-12.

9. Kurtzhals JA, Addae MM, Akanmori BD, et al. Anaemia caused by asymptomatic Plasmodium falciparum infection in semi-immune African schoolchildren. Trans R Soc Trop Med Hyg. 1999;93:623-7.

10. Dunyo S, Milligan P, Edwards T, Sutherland C, Targett G, Pinder M. Gametocytaemia after drug treatment of asymptomatic Plasmodium falciparum. PLoS Clin Trials. 2006;1:e20.

11. Baliraine FN, Afrane YA, Amenya DA, et al. High prevalence of asymptomatic Plasmodium falciparum infections in a highland area of western Kenya: a cohort study. J Infect Dis. 2009;200:66-74.

12. Mabunda S, Aponte JJ, Tiago A, Alonso P. A country-wide malaria survey in Mozambique. II. Malaria attributable proportion of fever and establishment of malaria case definition in children across different epidemiological settings. Malar J. 2009;8:74.

13. Vafa M, Troye-Blomberg M, Anchang J, Garcia A, Migot-Nabias F. Multiplicity of Plasmodium falciparum infection in asymptomatic children in Senegal: relation to transmission, age and erythrocyte variants. Malar J. 2008;7:17.

14. Dal-Bianco MP, Koster KB, Kombila UD, et al. High prevalence of asymptomatic Plasmodium falciparum infection in Gabonese adults. Am J Trop Med Hyg. 2007;77:939-42.

15. Geerligs PD, Brabin BJ, Eggelte TA. Analysis of the effects of malaria chemoprophylaxis in children on haematological responses, morbidity and mortality. Bull World Health Organ. 2003;81:205-16.

16. Korenromp EL, Armstrong-Schellenberg JR, Williams BG, Nahlen BL, Snow RW. Impact of malaria control on childhood anaemia in Africa-a quantitative review. Trop Med Int Health. 2004;9:1050-65.

17. Alonso PL, Lindsay SW, Armstrong Schellenberg JR, et al. A malaria control trial using insecticidetreated bed nets and targeted chemoprophylaxis 
in a rural area of The Gambia, west Africa. 2. Mortality and morbidity from malaria in the study area. Trans R Soc Trop Med Hyg. 1993;87:13-7.

18. Clarke SE, Jukes MC, Njagi JK, et al. Effect of intermittent preventive treatment of malaria on health and education in schoolchildren: a clusterrandomised, double-blind, placebo-controlled trial. Lancet. 2008;372:127-38.

19. Tiono AB, Ouedraogo A, Ogutu B, et al. A controlled, parallel, cluster-randomized trial of community-wide screening and treatment of asymptomatic carriers of Plasmodium falciparum in Burkina Faso. Malar J. 2013;12:79.

20. Makanga M, Bassat Q, Falade CO, et al. Efficacy and safety of artemether-lumefantrine in the treatment of acute, uncomplicated Plasmodium falciparum malaria: a pooled analysis. Am J Trop Med Hyg. 2011;85:793-804.

21. WHO. Model List of Essential Medicines. 2002. http://www.who.int/medicines/publications/ essentialmedicines/en/ Last accessed: March 8, 2013.
22. Mapping Malaria Risk in Africa (MARA) Collaboration. Burkina Faso: duration of the malaria transmission season. 2012. 10-6-2010. http://www.mara.org.za/pdfmaps/BukSeasonality. PDF. Last accessed: March 8, 2013.

23. De Allegri M, Louis VR, Tiendrebeogo J, Souares A, Ye M, Tozan Y, et al. Moving towards universal coverage with malaria control interventions: achievements and challenges in rural Burkina Faso. Int J Health Plann Manage. 2013;28:102-21.

24. Lengeler C. Insecticide-treated bed nets and curtains for preventing malaria. Cochrane Database Syst Rev. 2004;(2):CD000363.

25. Thuilliez J, Sissoko MS, Toure OB, Kamate P, Berthelemy JC, Doumbo OK. Malaria and primary education in Mali: a longitudinal study in the village of Doneguebougou. Soc Sci Med. 2010;71: 324-34. 